INL EXT-20-59619

Revision 0

\title{
Post-irradiation Examinations of the ATF Experiments - 2020 Status
}

September 2020

Fabiola Cappia 


\section{DISCLAIMER}

Neither the U.S. Government nor any agency thereof, nor any of their employees, makes any warranty, expressed or implied, or assumes any legal liability or responsibility for the accuracy, completeness, or usefulness, of any information, apparatus, product, or process disclosed, or represents that its use would not infringe privately owned rights.

References herein to any specific commercial product, process, or service by trade name, trade mark, manufacturer, or otherwise, does not necessarily constitute or imply its endorsement, recommendation, or favoring by the U.S. Government or any agency thereof. The views and opinions of authors expressed herein do not necessarily state or reflect those of the U.S. Government or any agency thereof. Being provided this document, directly or indirectly, shall not be construed to constitute a governmental export license or authorization. 


\title{
Post-irradiation Examinations of the ATF Experiments - 2020 Status
}

\author{
Fabiola Cappia
}

September 2020

Idaho National Laboratory

Characterization and Advanced PIE Division

Idaho Falls, Idaho 83415

http://www.inl.gov

Prepared for the

U.S. Department of Energy

Office of Nuclear Energy

Under DOE Idaho Operations Office

Contract DE-AC07-05ID14517 
Page intentionally left blank 


\section{SUMMARY}

This report contains the results of post-irradiation examination (PIE) of both Accident Tolerant Fuels-1 (ATF-1) rodlets and ATF-2 rodlets irradiated in the Advanced Test Reactor (ATR). The experiment is part of the U.S. Department of Energy (DOE) Nuclear Technology Research and Development (NTRD) program's Advanced Fuels Campaign (AFC). The ATF-1 PIE focused on the continuation of the analyses of five rodlets, one containing $\mathrm{U}_{3} \mathrm{Si}_{2}$ fuel, two containing $\mathrm{UN}-\mathrm{U}_{3} \mathrm{Si}_{5}$ composites, and two with $\mathrm{UN}-\mathrm{U}_{3} \mathrm{Si}_{2}$ composites. The non-destructive examinations of the $\mathrm{U}_{3} \mathrm{Si}_{2}$ rodlet showed results comparable to the previously investigated rodlets. The profilometry of the $\mathrm{UN}-\mathrm{U}_{3} \mathrm{Si}_{2}$ composites highlighted permanent deformation of the cladding at the pellet-pellet interface, suggesting that hourglassing of the composite pellet occurred during irradiation, causing increased localized stresses on the Zirlo cladding tube due to PelletCladding Mechanical Interaction (PCMI). The $\mathrm{UN}-\mathrm{U}_{3} \mathrm{Si}_{5}$ rodlets, which were contained in Kanthal cladding, did not show enhanced cladding deformation at the pellet interfaces; however, it is to be noted that the initial gap of these two rodlets was larger than typical light water reactor (LWR) gaps. The larger gap might have been sufficient to accommodate the fuel swelling without having contact between the fuel and cladding, explaining the absence of PCMI. Regarding the fission products, no axial redistribution of the major gamma emitters was observed in any of the composite rodlets. Fission gas measurements on the $\mathrm{UN}-\mathrm{U}_{3} \mathrm{Si}_{5}$ rodlets also has been performed. The estimated fission gas release, based on the calculated fission product inventory, remains limited, with a higher fission gas release for the rodlet that experienced a higher power.

In addition to the PIE data on the ATF-1 concepts, PIE on the baseline rodlets part of the ATF-2 tests irradiated in the water loop installed in ATR commenced this year. The data have been collected to provide baseline PIE data to support future testing in the INL Transient Reactor Test (TREAT) facility. Moreover, the data from these baseline rods will provide UO2-Zr-4 performance data to which the data of the ATF concepts can be compared directly. The analyses performed included: visual examinations, axial gamma scanning, neutron radiography and profilometry. All the data collected showed a performance consistent with expectations for this fuel system at low burnup.

Finally, a new pycnometer, in conjunction with a high precision balance, has been installed in the hot cells. The system allows the measurements of fuel swelling and its variation with burnup, which is an important fuel characteristic influencing the fuel performance. The new pycnometer expands the portfolio of available PIE techniques for the current program and other users.

\section{ACKNOWLEDGEMENTS}

The author would like to acknowledge the operators and engineers of the Hot Fuel Examination Facility (HFEF) who executed the PIE. I am indebted to

K. Williams, J. Skinner, and E. Beverly for administrative support on this project. 
Page intentionally left blank 


\section{CONTENTS}

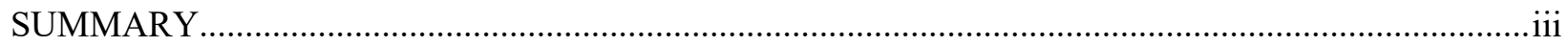

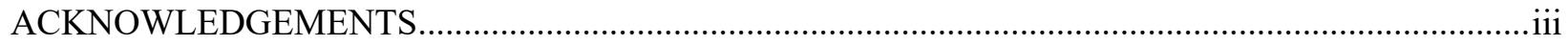

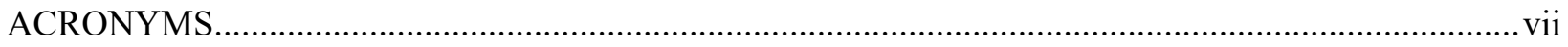

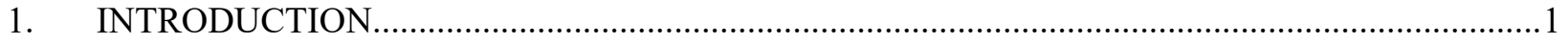

2. PIE CAPABILITY DEVELOPMENTS .......................................................................... 1

3. SUMMARY OF EXPERIMENT AND IRRADIATION CONDITIONS......................................... 3

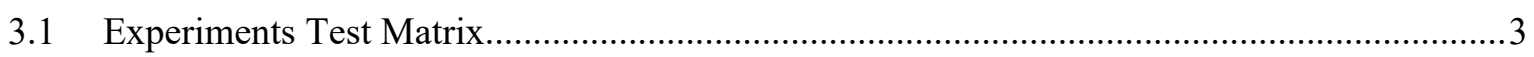

3.2 Irradiation History...........................................................................................

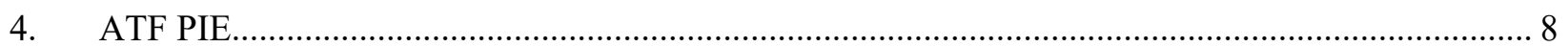

4.1 ATF-41 and ATF-44: PIE results and discussion............................................................. 8

4.2 ATF-10, ATF-30 and ATF-34: PIE Results and Discussion................................................ 13

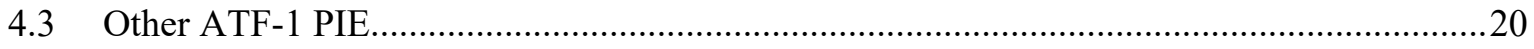

4.4 ATF-2 PIE

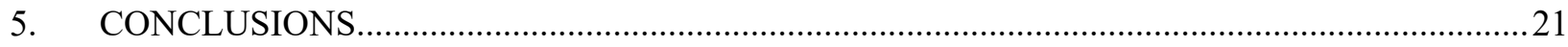

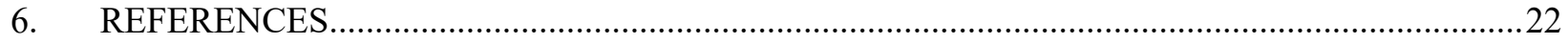

\section{FIGURES}

Figure 1. Picture of the pycnometer equipment installed in the hot cells.......................................

Figure 2. Irradiation history data for L41, L44 and L45. (a) Linear Heat Generation Rate (LHGR),

(b) Fuel centerline temperature, (c) Cladding inner peak temperature............................8

Figure 3. Irradiation history data for W01, WB2 and WB6. (a) Linear Heat Generation Rate (LHGR), (b) Fuel centerline temperature, (c) Cladding inner peak temperature............. 8

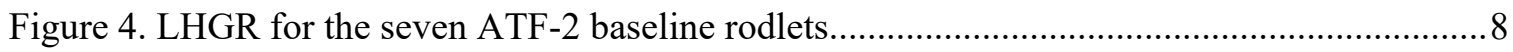

Figure 5. Visual examination of (a) L41 (ATF-41) and (b) L44 (ATF-44)..................................

Figure 6. (a) Thermal and (b) Epithermal neutron radiography of L41 and L44........................ 10

Figure 7. Cladding outer diameter of (a) L41 and (b) L44. The black dots represent the measurements with uncertainty, while the solid red line is the as-fabricated value of the

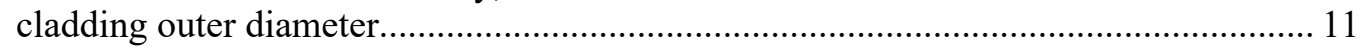

Figure 8. Axial gamma distribution of selected fission products for (a) L41 and (b) L44............ 12

Figure 9. Radial distribution of selected fission products from gamma tomography on rodlet L44. (a) $95 \mathrm{Zr}$, (b) $137 \mathrm{Cs}$, (c) $106 \mathrm{Ru}-106 \mathrm{Rh}$. All the data were collected at the axial mid

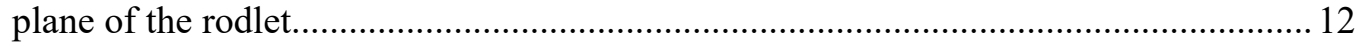

Figure 10. (a)-(c) Visual examinations of rodlet (a) W01 (b) WB2 and (c) WB6........................14

Figure 11. (a) Thermal neutron radiography of the three rodlets, (b) epithermal neutron radiography at the same azimuthal angle 
Figure 12. Measured cladding outer diameter for rodlet W01 (black symbols). For reference, the as-fabricated value is shown (red line) as well as the average profilometry results from one of the previous analyzed U3Si2-Zirlo rodlets [10].

Figure 13. Cladding outer diameter data for WB2 (black symbols) and as-fabricated rodlet outer diameter (solid red line)

Figure 14. Cladding outer diameter data for WB6 (black symbols) and as-fabricated rodlet outer diameter (solid red line)

Figure 15. Axial gamma profile of Cs-137 and Ce/Pr-144 for rodlets (a) W01, (b) WB2, and (c) WB6.

Figure 16. Radial distribution of selected fission products from gamma tomography on rodlet WB2. (a) $95 \mathrm{Zr}$, (b) $137 \mathrm{Cs}$, (c) 106Ru-106Rh. All the data were collected at the axial mid plane of the rodlet.

Figure 17. Visual examination of capsule ATF-75 (rodlet ATF-OF3)

\section{TABLES}

Table 1. ATF-1 experiment test matrix and predicted discharge burnup.................................... 3

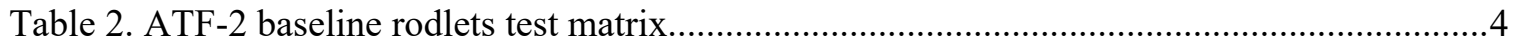

Table 3. Fission gas release data and calculated burnup and fission density for the three LANL rodlets. 


\section{ACRONYMS}

$\begin{array}{ll}\text { AFC } & \text { Advanced Fuels Campaign } \\ \text { ATF } & \text { Accident Tolerant Fuel } \\ \text { ATR } & \text { Advanced Test Reactor } \\ \text { DOE } & \text { Department of Energy } \\ \text { FCCI } & \text { fuel-cladding chemical interaction } \\ \text { FGR } & \text { fission gas release } \\ \text { HFEF } & \text { Hot Fuel Examination Facility } \\ \text { INL } & \text { Idaho National Laboratory } \\ \text { LANL } & \text { Los Alamos Nuclear Laboratory } \\ \text { LHGR } & \text { Linear Heat Generation Rate } \\ \text { LWR } & \text { Light Water Reactor } \\ \text { NTRD } & \text { Nuclear Technology Research and Development } \\ \text { ORNL } & \text { Oak Ridge Nuclear Laboratory } \\ \text { PCMI } & \text { Pellet-Cladding Mechanical Interaction } \\ \text { PIE } & \text { Post-irradiation Examination } \\ \text { PWR } & \text { pressurized water reactor } \\ \text { TREAT } & \text { Transient Reactor Test (facility) }\end{array}$


Page intentionally left blank 


\section{Post-irradiation Examinations of the ATF Experiments - 2020 Status}

\section{INTRODUCTION}

A fueled experimental campaign part of the U.S. Department of Energy (DOE) Nuclear Technology Research and Development (NTRD) program's Advanced Fuels Campaign (AFC) is being conducted in the Idaho National Laboratory (INL) Advanced Test Reactor (ATR). The main goal of the Accident Tolerant Fuel (ATF) campaign is to demonstrate the improved performance, both in terms of economics and safety, of new fuel and cladding concepts with respect to the standard Light Water Reactor (LWR) fuels, i.e., $\mathrm{UO}_{2}$ and zircaloy [1]. The campaign started in 2015 with a series of dry-capsule irradiations, the so-called ATF-1 irradiations, to enable early screening of concepts by providing assessment of fuel pellet performance and evaluation of potential fuel-cladding interaction with effective investments. In addition to the ATF-1 irradiations, the more advanced concepts have been inserted in a pressurized water loop at the center of the ATR core in 2018 [2]. In the ATR loop, the ATF rodlets are irradiated in an environment fully prototypical of pressurized water reactors (PWRs).

As the campaign advances through the ATF-2 irradiations, the remaining ATF-1 capsules have been discharged this year. Post-Irradiation Examination (PIE) results from the ATF-1 capsules continued to be collected at the Idaho National Laboratory hot cells. Moreover, in this fiscal year, the first set of rodlets part of the second phase of the campaign have been discharged from the pressurized water loop installed at the center of the ATR core and are being examined.

In addition to the PIE on the various ATF rodlets, new PIE capabilities have been installed to expand the portfolio of techniques that can provide performance-relevant data on the fuel systems under investigations. Section 2 reports the details of the new installation in the hot cells. The overall test matrices are summarized in Section 3 with focus on the irradiation conditions of the rodlets investigated this year, and PIE results are shown in Section 4.

\section{PIE CAPABILITY DEVELOPMENTS}

In the effort to continuously expand the available PIE techniques to measure and quantify critical fuel properties and their evolution with burnup, the ATF Campaign has installed in the hot cells of the Hot Fuel Examination Facility (HFEF) a helium pycnometer which measures irradiated fuel volume and, in conjunction with a high precision balance part of the same equipment, allows the determination of irradiated fuel density.

The volume change of the active fuel column upon burnup accumulation is one of the most important phenomenon due to its impact on vital aspects of fuel performance, such as the stresses induced onto the cladding by fuel swelling, changes in heat transfer in the fuel-to-cladding gap and fuel thermal profiles $[3,4]$. The fuel swelling caused by fission products is generally divided into swelling due to solid fission products and gaseous fission products. The swelling due to the solid fission products is determined by the volume variation associated with the substitution of each atom of fission products, being predominant when they precipitate. A small contribution can arise due to species substitution within the crystal lattice [5]. Gaseous swelling is by far the major contributor to volume change due to the low density of the gaseous species compared to the hosting fuel matrix [6]. Gaseous fuel swelling can be inferred by twodimensional measurements of the porosity using microscopy-based techniques, but, generally, several resolutions and type of microscopes (i.e., Transmission and Scanning Electron Microscopes and Optical Microscopes) need to be combined for comprehensive measurements. On the other side, direct measurements of the fuel density will provide the information in the most convenient way. Density measurements on irradiated fuel have generally been performed by the buoyancy technique, which is based on the Archimedes principle using an auxiliary liquid. The solid is weighed in air and then again in an auxiliary liquid with known density (e.g., water, methanol, monobromobenzene, 1,1,2,2-

tetrabromoethane). The temperature of the liquid must be taken into account, as this can cause changes in 
the sample density results. Water is generally not used in the hot cell. Methanol is commonly used but might suffer from evaporation/bubbling when in contact with fuel due to the decay heat. Higher density fluids might not wet completely the small cracks, biasing the results. In addition, the oil impregnation is not practical if the sample needs to be used for further post-irradiation examinations, e.g., bulk diffusivity measurements. Another method that can be employed for nuclear fuels is the pycnometry, which measures the sample volume with high accuracy. The volume of the sample is measured in a calibrated chamber filled with gas, generally helium. The mass is measured separately by a high precision balance and, from the two measurements, the density is calculated. The method is particularly advantageous for powders, does not suffer from the limitations explained above related to the use of a high-density liquid impregnation, and it ensures no reaction can occur between the sample and the measuring fluid. An overview of the instrumentation after installation in cell is shown in Figure 1. The engineering qualification process was completed, and the system is ready to be used on ATF fuel concepts such as UN or silicides. 


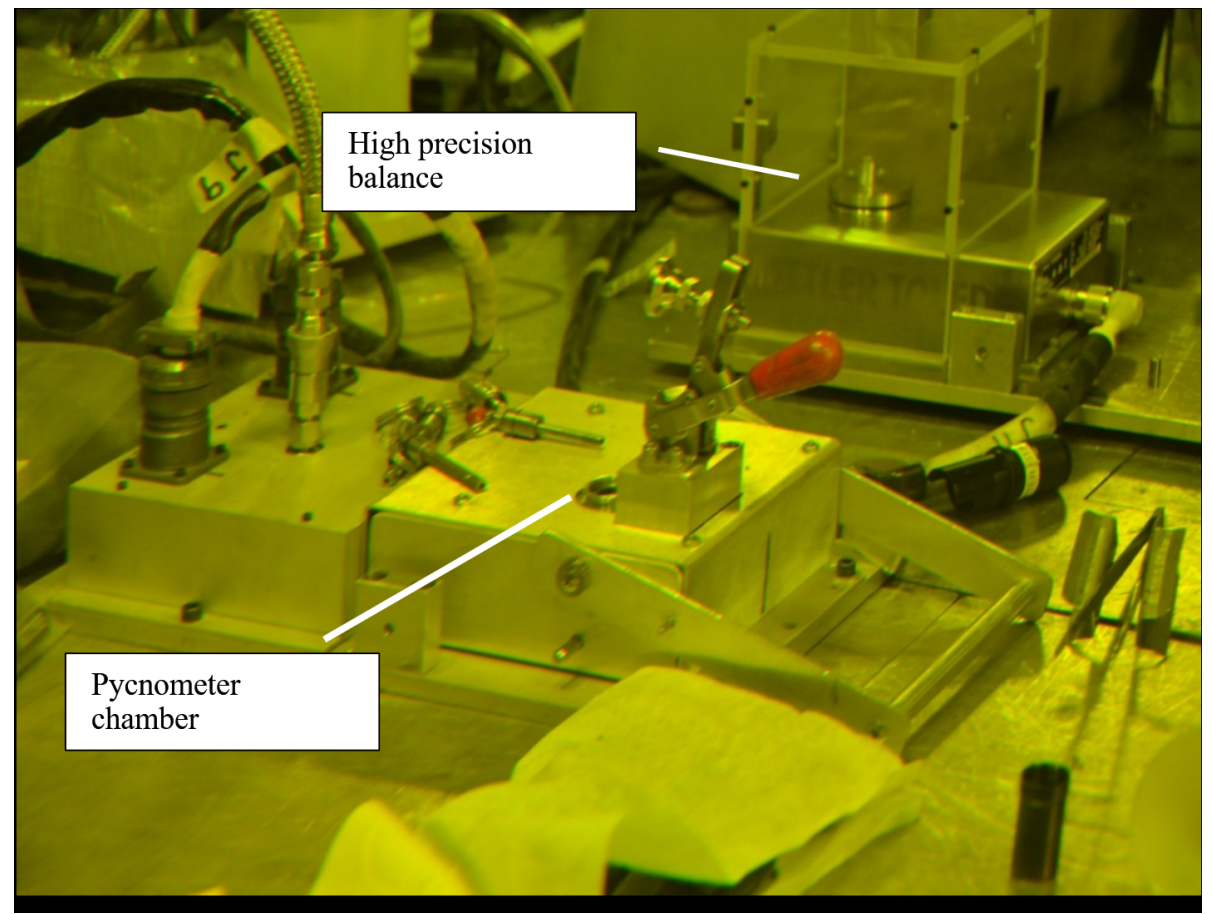

Figure 1. Picture of the pycnometer equipment installed in the hot cells.

\section{SUMMARY OF EXPERIMENT AND IRRADIATION CONDITIONS}

\subsection{Experiments Test Matrix}

The complete test matrix of the ATF-1 experiments is reported in Table 1. PIE on some of the capsules and rodlets was completed in previous years and reported elsewhere. The focus of this year was on five rodlets that had started PIE on the capsules in 2019, namely: the two rodlets containing $\mathrm{UN}-\mathrm{U}_{3} \mathrm{Si}_{5}$ composite fuel with Kanthal cladding sponsored by Los Alamos National Laboratory (ATF-L41 and ATF-L44) and three of the Westinghouse-sponsored concepts, ATF-W01 ( $\mathrm{U}_{3} \mathrm{Si}_{2}-\mathrm{Zirlo}$ ), ATF-WB2, and ATF-WB6 $\left(\mathrm{UN}-\mathrm{U}_{3} \mathrm{Si}_{2}\right)$. The remaining capsules have been received in May 2020 and PIE on the capsules started.

In addition to the ATF-1 capsules, seven baseline rodlets from the ATF-2 also commenced PIE this year. The complete test matrix for the ATF-2 baseline rods is reported in Table 2.

Table 1. ATF-1 experiment test matrix and predicted discharge burnup.

\begin{tabular}{lllllll}
\hline Capsule ID & Rodlet ID & Concept Lead & \multicolumn{1}{c}{ Fuel Type } & \multicolumn{1}{c}{$\begin{array}{c}\text { Cladding Type } \\
\text { Discharge } \\
\text { burnup } \\
\text { (GWd/tHM) }\end{array}$} \\
\hline ATF-00 & $\mathrm{A} 01$ & Framatome & $\mathrm{UO}_{2}$ & Zirc-4 & $7.2^{*}$ \\
ATF-01 & $\mathrm{A} 02$ & Framatome & $\mathrm{UO}_{2}$ & Zirc-4 & 40.03 \\
ATF-02 & $\mathrm{A} 03$ & Framatome & $\mathrm{UO}_{2}+\mathrm{SiC}$ & Zirc-4 & 38.98 \\
ATF-03 & $\mathrm{A} 04$ & Framatome & $\mathrm{UO}_{2}+\mathrm{SiC}$ & Zirc-4 & $4.9^{*}$ \\
ATF-04 & $\mathrm{A} 05$ & Framatome & $\mathrm{UO}_{2}+$ Diamond & Zirc-4 & $7.2^{*}$ \\
ATF-05 & $\mathrm{A} 06$ & Framatome & $\mathrm{UO}_{2}+$ Diamond & Zirc-4 & 39.47 \\
ATF-06 & $\mathrm{G} 01$ & General Electric & $\mathrm{UO}_{2}$ & Alloy-33 & 18.4 \\
ATF-07 & G02 & General Electric & $\mathrm{UO}_{2}$ & Alloy-33 & 39.48
\end{tabular}




\begin{tabular}{|c|c|c|c|c|c|}
\hline ATF-08 & G03 & General Electric & $\mathrm{UO}_{2}$ & APMT & 18.3 \\
\hline ATF-09 & G04 & General Electric & $\mathrm{UO}_{2}$ & APMT & 34.48 \\
\hline ATF-10 & W01 & Westinghouse & $\mathrm{U}_{3} \mathrm{Si}_{2}$ & ZIRLO & 21.4 \\
\hline ATF-11 & W02 & Westinghouse & $\mathrm{U}_{3} \mathrm{Si}_{2}$ & ZIRLO & 34.48 \\
\hline ATF-12 & W03 & Westinghouse & $\mathrm{U}_{3} \mathrm{Si}_{2}$ & ZIRLO & 35.26 \\
\hline ATF-13 & W04 & Westinghouse & $\mathrm{U}_{3} \mathrm{Si}_{2}$ & ZIRLO & $17.1 *$ \\
\hline ATF-14 & W05 & Westinghouse & $\mathrm{U}_{3} \mathrm{Si}_{2}$ & ZIRLO & 44.49 \\
\hline ATF-15 & W06 & Westinghouse & $\mathrm{U}_{3} \mathrm{Si}_{2}$ & ZIRLO & $19.6^{*}$ \\
\hline ATF-17 & FCA-L2 & ORNL & $\mathrm{UO}_{2}$ & FeCrAl Alloy & 29.78 \\
\hline ATF-18 & FCA-L3 & ORNL & $\mathrm{UO}_{2}$ & FeCrAl Alloy & 10.4 \\
\hline ATF-20 & FCA-L5 & ORNL & $\mathrm{UO}_{2}$ & FeCrAl Alloy & 29.92 \\
\hline ATF-29 & WB1 & Westinghouse & $\mathrm{UN}-\mathrm{U}_{3} \mathrm{Si}_{2}$ & ZIRLO & 18.56 \\
\hline ATF-30 & WB2 & Westinghouse & $\mathrm{UN}-\mathrm{U}_{3} \mathrm{Si}_{2}$ & ZIRLO & 19.2 \\
\hline ATF-31 & WB3 & Westinghouse & $\mathrm{UN}-\mathrm{U}_{3} \mathrm{Si}_{2}$ & ZIRLO & 27.16 \\
\hline ATF-32 & WB4 & Westinghouse & $\mathrm{UN}-\mathrm{U}_{3} \mathrm{Si}_{2}$ & ZIRLO & 18.56 \\
\hline ATF-33 & WB5 & Westinghouse & $\mathrm{UN}-\mathrm{U}_{3} \mathrm{Si}_{2}$ & ZIRLO & 26.16 \\
\hline ATF-34 & WB6 & Westinghouse & $\mathrm{UN}-\mathrm{U}_{3} \mathrm{Si}_{2}$ & ZIRLO & 20.4 \\
\hline ATF-41 & L41 & LANL & $\mathrm{UN}-\mathrm{U}_{3} \mathrm{Si}_{5}$ & $\begin{array}{l}\text { Kanthal-AF } \\
\text { (FeCrAl Alloy) }\end{array}$ & 10 \\
\hline ATF-44 & L44 & LANL & $\mathrm{UN}-\mathrm{U}_{3} \mathrm{Si}_{5}$ & $\begin{array}{l}\text { Kanthal-AF } \\
\text { (FeCrAl Alloy) }\end{array}$ & 9.5 \\
\hline ATF-45 & L45 & LANL & $\mathrm{U}_{3} \mathrm{Si}_{5}$ & $\begin{array}{l}\text { Kanthal-AF } \\
\text { (FeCrAl Alloy) }\end{array}$ & 13.2 \\
\hline ATF-73 & FCCI-73 & ORNL & $\mathrm{UO}_{2}$ & FeCrAl Alloy** & 8.7 \\
\hline ATF-74 & FCCI-74 & ORNL & $\mathrm{UO}_{2}$ & FeCrAl Alloy** & 26 \\
\hline ATF-75 & FCCI-75 & ORNL & $\mathrm{UO}_{2}$ & FeCrAl Alloy** & 26 \\
\hline \multicolumn{6}{|c|}{$\begin{array}{l}\text { * From PIE data } \\
\text { ** The rodlets were composed of different diffusion-couple style experiments with FeCrAl disks of different } \\
\text { composition }\end{array}$} \\
\hline Rodlet ID & \multicolumn{2}{|c|}{ Fuel Type } & Cladding Type & \multicolumn{2}{|c|}{$\begin{array}{l}\text { Discharge burnup } \\
\text { (GWd/tHM) }\end{array}$} \\
\hline R04 & \multicolumn{2}{|c|}{$\mathrm{UO}_{2}$} & Zirc-4 & \multicolumn{2}{|l|}{9.32} \\
\hline R05 & \multicolumn{2}{|c|}{$\mathrm{UO}_{2}$} & Zirc-4 & \multicolumn{2}{|l|}{9.27} \\
\hline R06 & \multicolumn{2}{|c|}{$\mathrm{UO}_{2}$} & Zirc-4 & \multicolumn{2}{|l|}{9.54} \\
\hline R07 & \multicolumn{2}{|c|}{$\mathrm{UO}_{2}$} & Zirc-4 & \multicolumn{2}{|l|}{9.23} \\
\hline R08 & \multicolumn{2}{|c|}{$\mathrm{UO}_{2}$} & Zirc-4 & \multicolumn{2}{|l|}{9.47} \\
\hline R09 & \multicolumn{2}{|c|}{$\mathrm{UO}_{2}$} & Zirc-4 & \multicolumn{2}{|l|}{9.37} \\
\hline R10 & \multicolumn{2}{|c|}{$\mathrm{UO}_{2}$} & Zirc-4 & \multicolumn{2}{|c|}{10.29} \\
\hline R11 & \multicolumn{2}{|c|}{$\mathrm{UO}_{2}$} & Zirc-4 & \multicolumn{2}{|c|}{ In irradiation } \\
\hline
\end{tabular}

\subsection{Irradiation History}

The irradiation history data of ATF-L41 and ATF-L44 from Ref. [7]are reported in Figure 2. For comparison, the data from ATF-L45 are also shown. The difference in the Linear Heat Generation Rate (LHGR) between L41 and L44 reflects the different initial enrichment of the two rodlets, 5.27 and 2.69 
$\mathrm{wt} \%{ }^{235} \mathrm{U}$, respectively, which resulted in different operating temperatures.

Figure 3 shows the data for the three Westinghouse rodlets. The two composite rodlets WB2 and WB6 had similar LHGR, but the initial filling gas composition of WB6 contained $75 \%$ Ar and 25\% He vs $100 \% \mathrm{He}$ for WB2, resulting in the higher fuel temperature predicted for WB6 in Figure 3b. The average LHGR of W01 was considerably lower than the LHGR of the two previously analyzed rods from this batch, as W01 had an average LHGR of $232 \mathrm{~W} / \mathrm{cm}$ versus $395 \mathrm{~W} / \mathrm{cm}$ for W04 and $422 \mathrm{~W} / \mathrm{cm}$ for W06.

Finally, the LHGR for the seven ATF-2 baseline rodlets is reported in Figure 4 [8,9]. Six of them were contained in the same tier and had the same power history; R10 was irradiated in a different tier at a slightly higher power. 


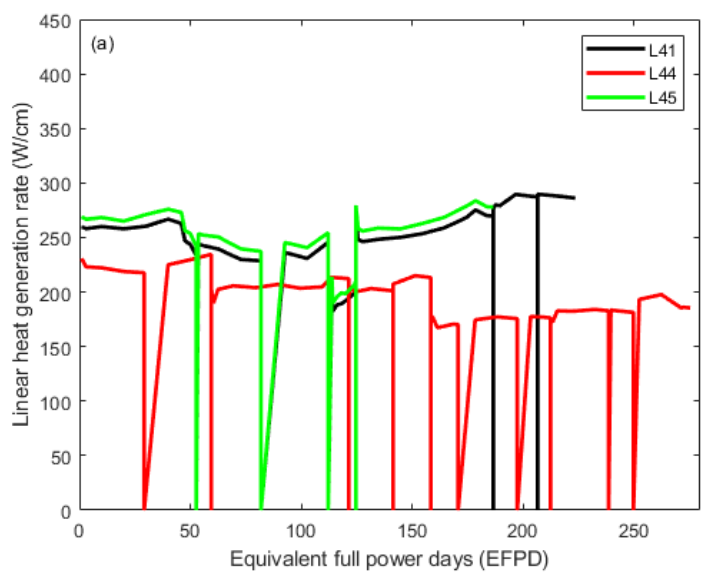

(a)

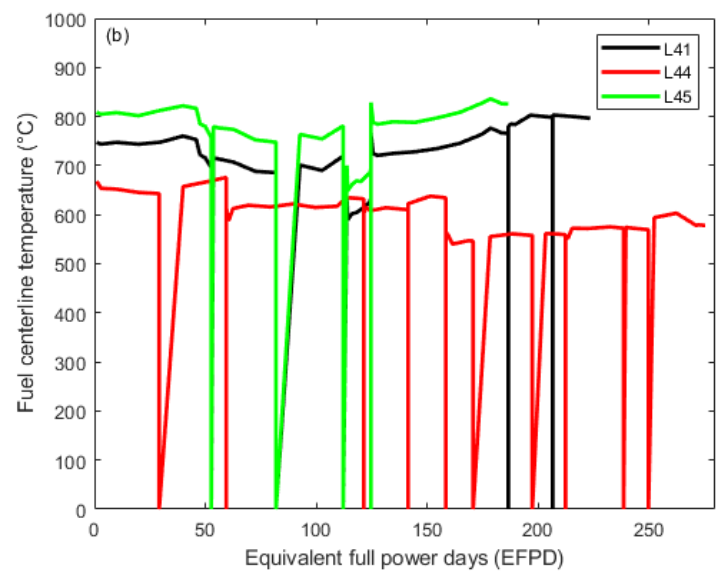

(b)

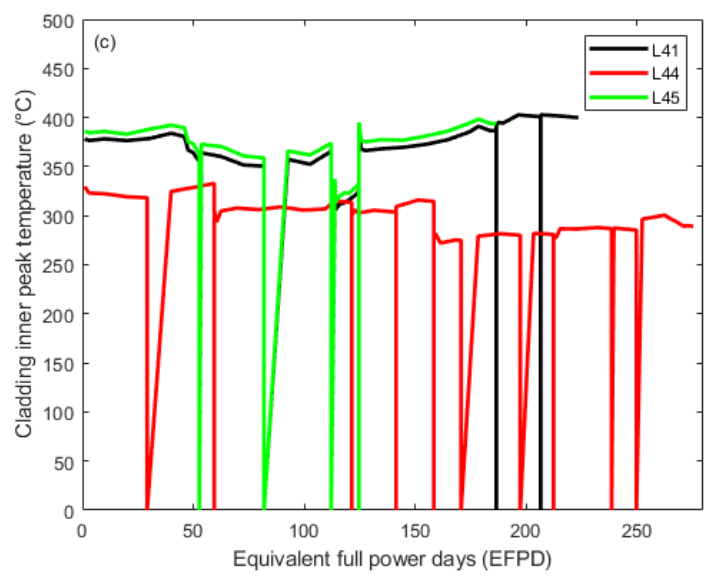

(c)

Figure 2. Irradiation history data for L41, L44 and L45. (a) Linear Heat Generation Rate (LHGR), (b) Fuel centerline temperature, (c) Cladding inner peak temperature. 


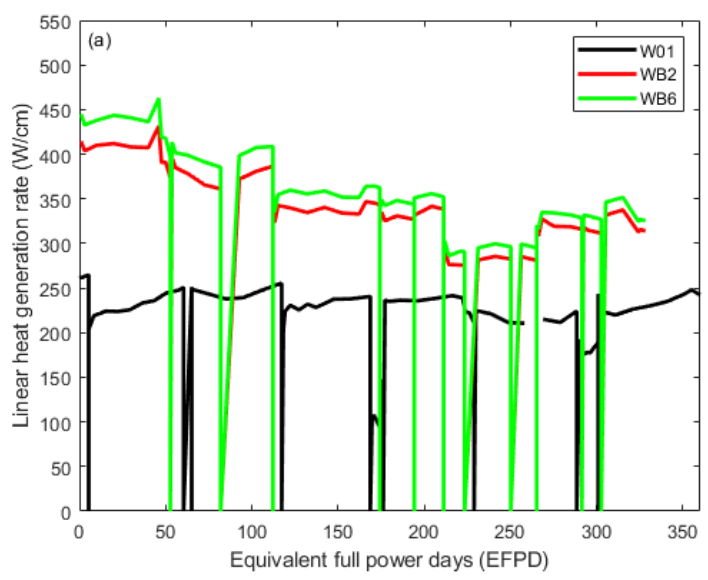

(a)

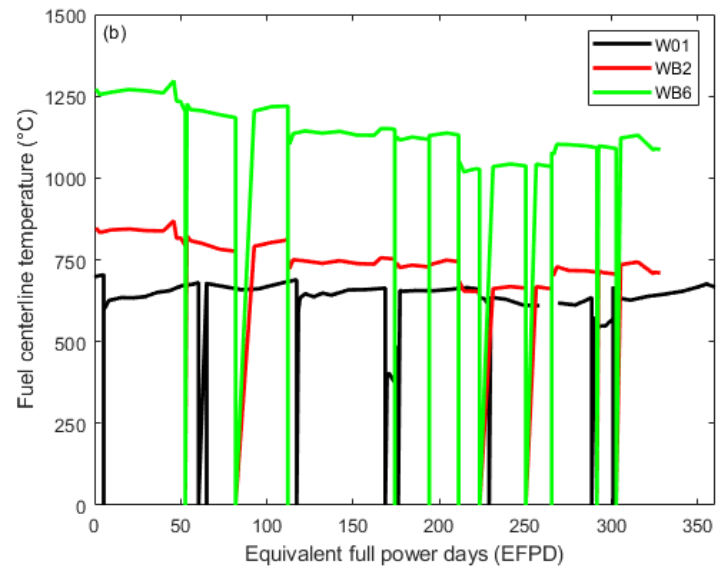

(b)

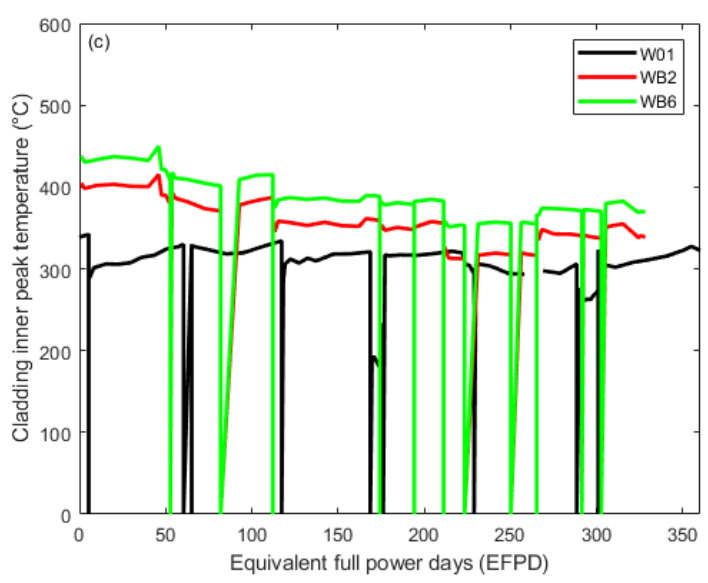

(c)

Figure 3. Irradiation history data for W01, WB2 and WB6. (a) Linear Heat Generation Rate (LHGR), (b) Fuel centerline temperature, (c) Cladding inner peak temperature. 


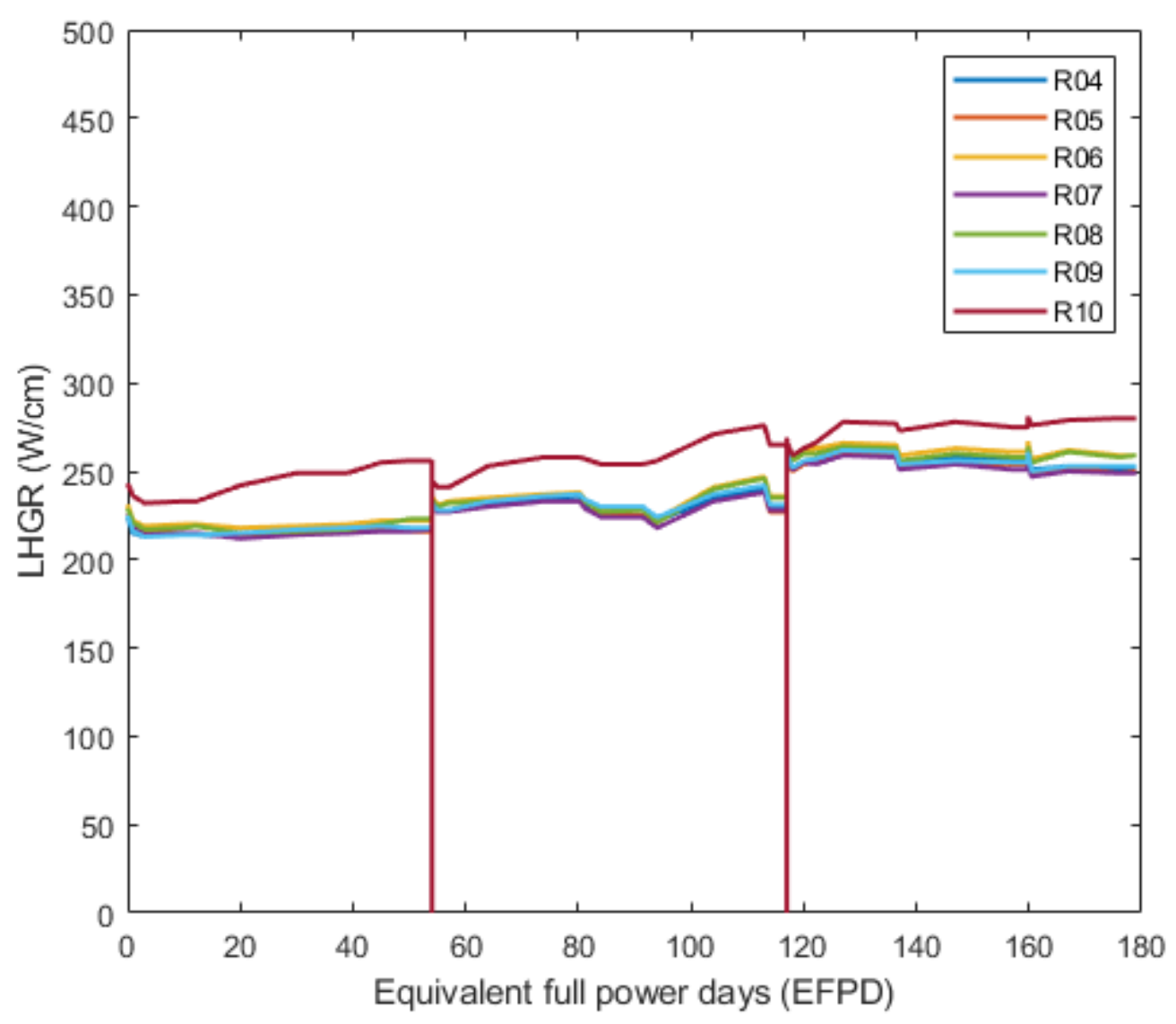

Figure 4. LHGR for the seven ATF-2 baseline rodlets.

\section{ATF PIE}

PIEs were performed at the INL HFEF. The examinations were divided in baseline non-destructive examinations, i.e., visual examinations, neutron radiography, cladding profilometry, gamma axial scan and gamma radial tomography, and baseline destructive, which included puncturing to measure fission gas release, chemical burnup analyses and optical metallography. For each of them, the same measurement protocols used previously for the other ATF PIE have been followed. Details of each of the experimental techniques used can be found in the previous PIE reports [10,11].

\subsection{ATF-41 and ATF-44: PIE results and discussion}

Visual examinations were performed through the cell window. Photographic records of the examinations are displayed in Figure 5. The rodlets did not present unusual features; the cladding surface appeared still shiny since no contact with the coolant occurs for these encapsulated rodlets. Darkening occurred at the end cap weld areas, which is a phenomenon that was observed in all the ATF-1 rodlets examined so far. 


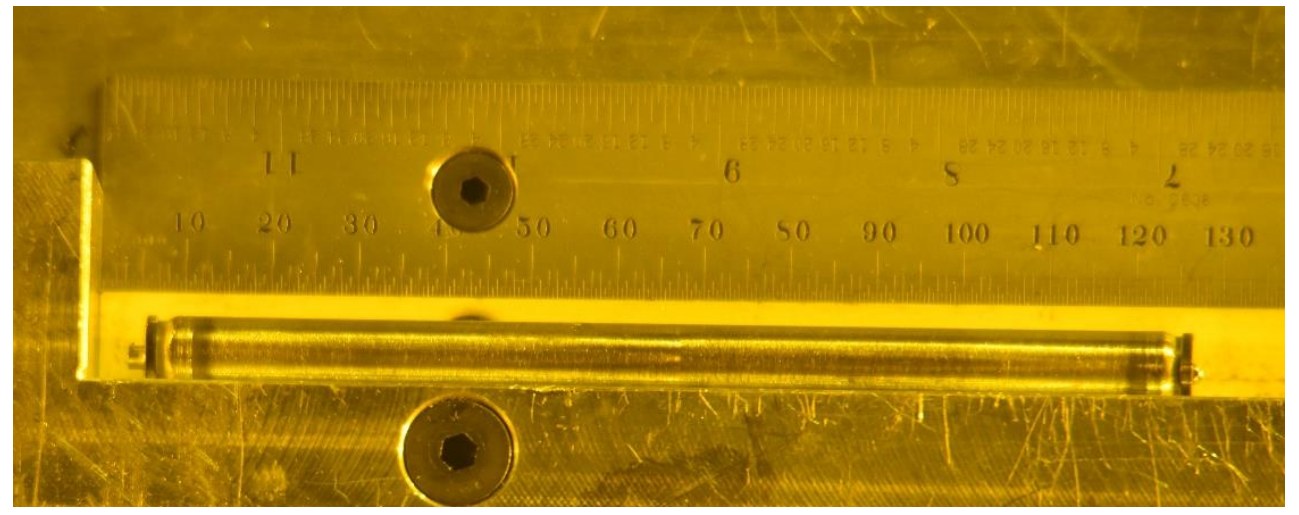

(a)

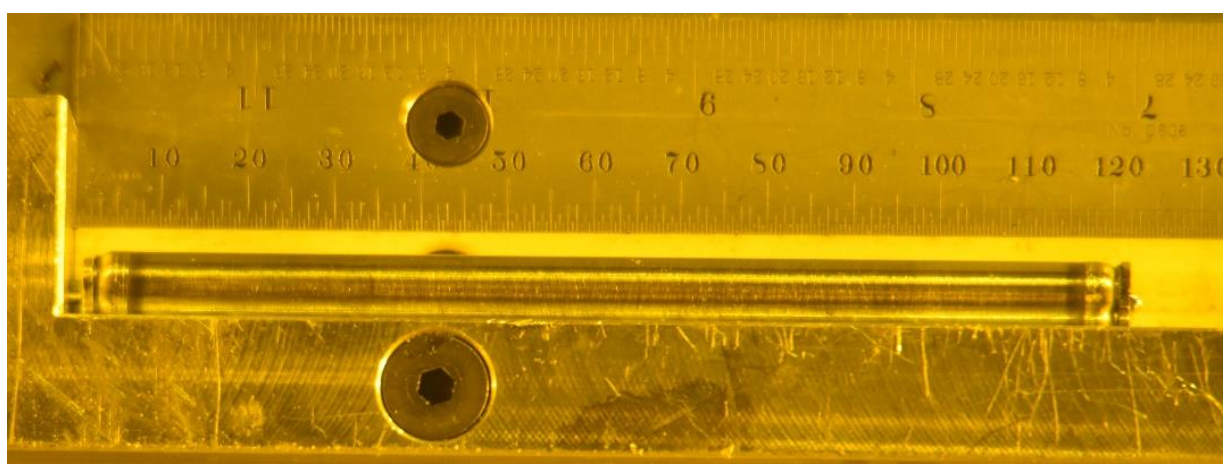

(b)

Figure 5. Visual examination of (a) L41 (ATF-41) and (b) L44 (ATF-44).

Figure 6 shows the neutron radiography of the two rodlets. The neutron radiographs from the other two orientations showed similar results. Overall, for both rodlets, the fuel stack does not present large cracking, with a single exception. The last enriched pellet in both rodlets shows an axial crack at the outermost periphery of the pellet. Further cracking has occurred in the bottom depleted pellet of L44, and some material has fallen at the bottom of the end cap, as indicated by the arrow in Figure 6a. The last three pellets of L41 and L44 are slightly misaligned, suggesting that the gap is still open and the pellets are free to move inside the cladding tube. It has to be noted that these rodlets were fabricated with a larger gap compared to the standard gap dimension of PWR rods as the swelling behavior of $\mathrm{UN}_{-} \mathrm{U}_{3} \mathrm{Si}_{5}$ fuel was not known and a conservative approach was taken. 


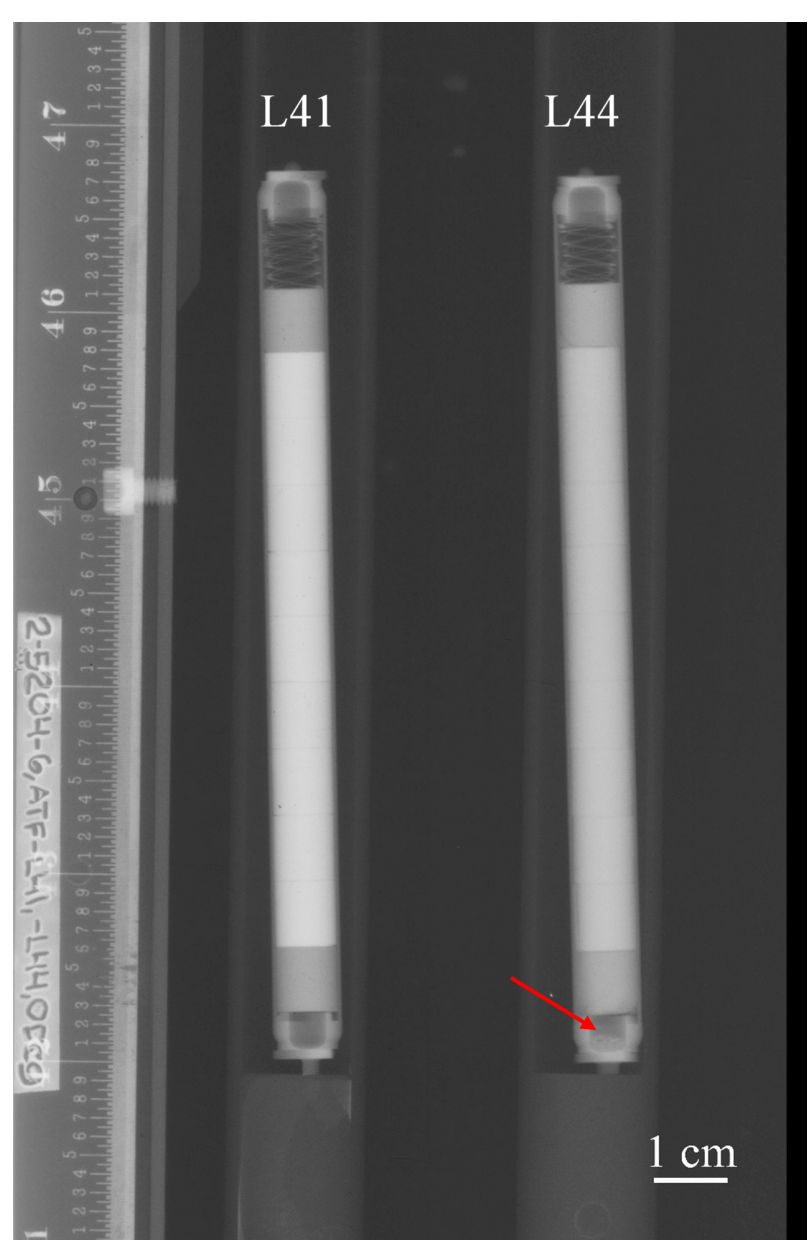

(a)

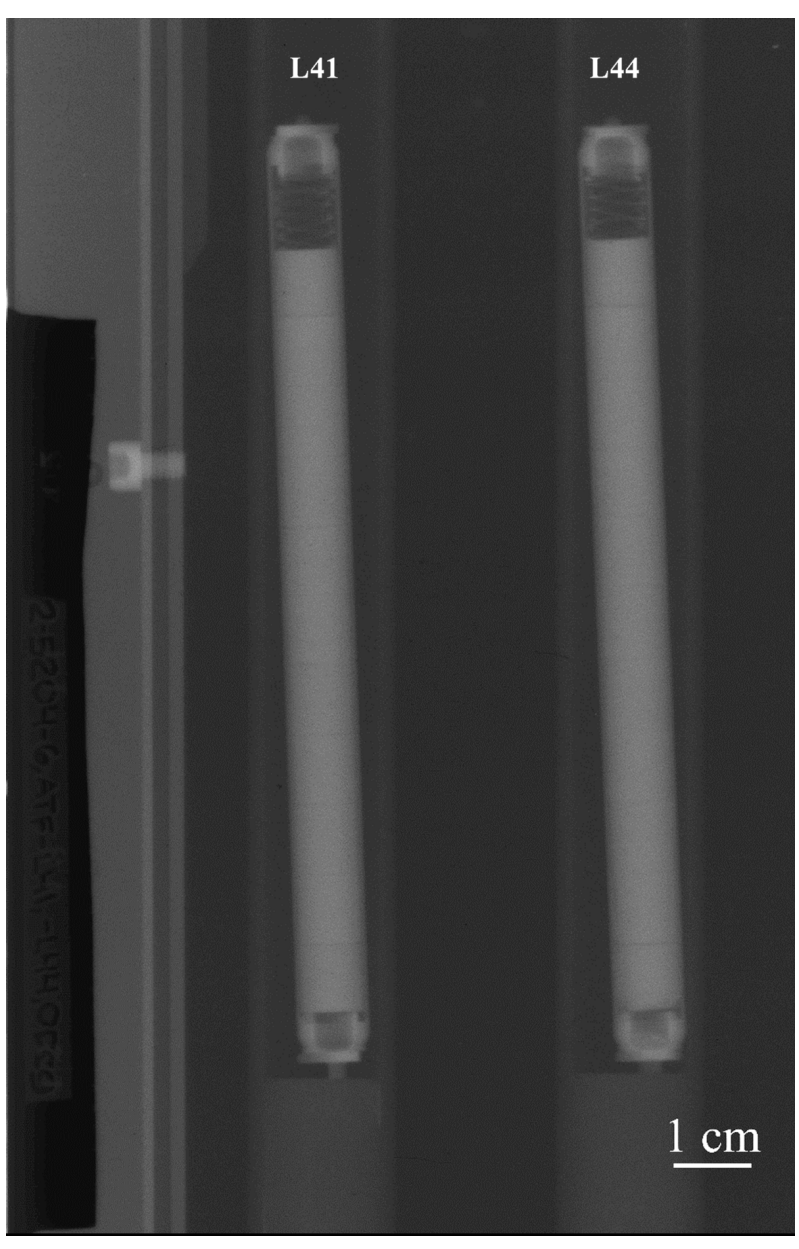

(b)

Figure 6. (a) Thermal and (b) Epithermal neutron radiography of L41 and L44.

No significant cladding outer diameter change was measured using profilometry (Figure 7) in either rodlet. Along the entire axial length, the measured cladding outer diameter remains close to the as-fabricated nominal value.

Finally, gamma spectroscopy was performed to complete the non-destructive examinations. Figure 8 shows the typical axial profile of ${ }^{137} \mathrm{Cs}$ and ${ }^{144} \mathrm{Ce}-{ }^{144} \mathrm{Pr}$, which are commonly used as burnup monitors. In both rodlets, an asymmetric behavior of the fission products is observed axially, due to the neutron flux gradient the rodlets experienced, as already observed in the companion rodlet L45 [10]. Gamma tomography was performed on rodlet L44. Radial distribution of selected fission products at the mid axial plane are shown in Figure 9. No radial redistribution of fission products occurred, not even for the volatile Cs. Peripheral enrichment is visible due to the increased burnup at the pellet rim. 
(b)

Figure 7. Cladding outer diameter of (a) L41 and (b) L44. The black dots represent the measurements with uncertainty, while the solid red line is the as-fabricated value of the cladding outer diameter.

(a)

(b)

Figure 8. Axial gamma distribution of selected fission products for (a) L41 and (b) L44. 


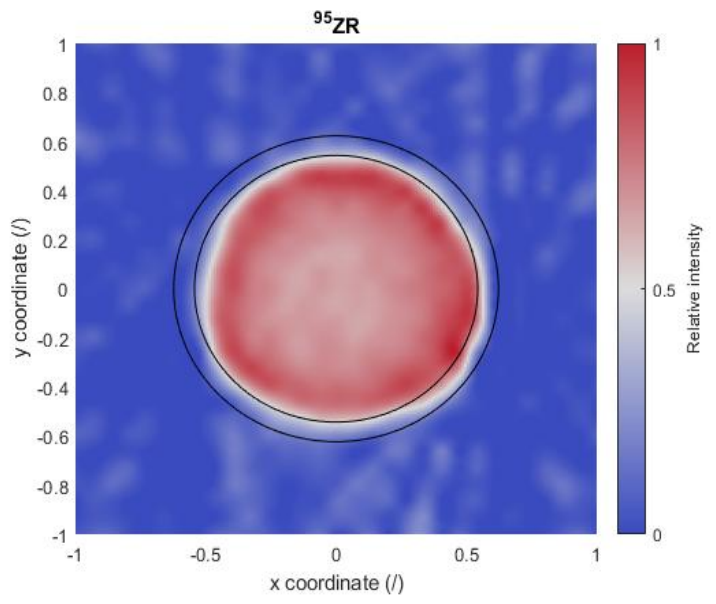

(a)

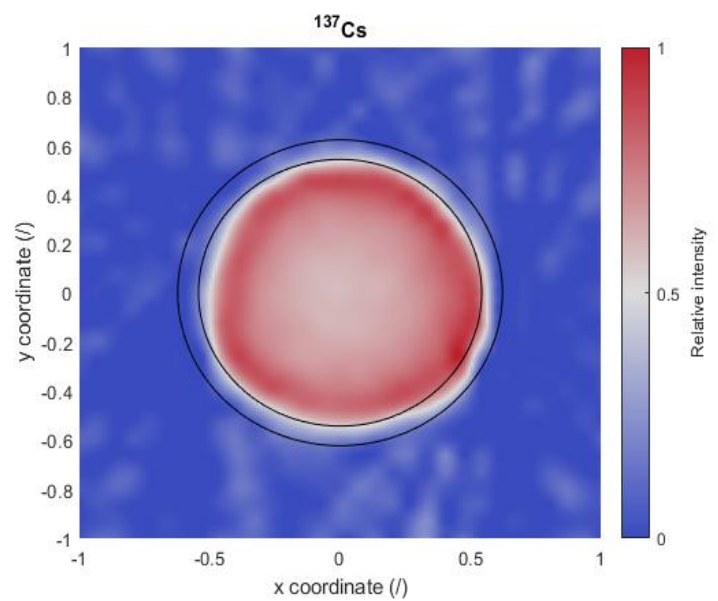

(b)

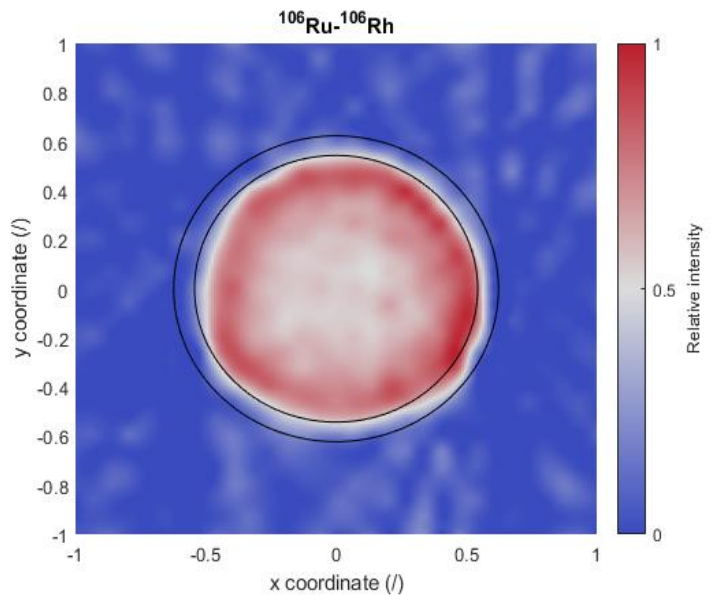

(c)

Figure 9. Radial distribution of selected fission products from gamma tomography on rodlet L44. (a) 95Zr, (b) $137 \mathrm{Cs}$, (c) $106 \mathrm{Ru}-106 \mathrm{Rh}$. All the data were collected at the axial mid plane of the rodlet. 
After completion of the non-destructive examinations, the rodlets were punctured to measure the released gas. The results are summarized in Table 3 for both the rodlets presently investigated and for the last rodlet belonging to this irradiation campaign, which was previously analyzed [10]. The measured plenum pressure has been translated into estimated fission gas release (FGR) values based on the gas inventory derived from the calculated fission density reported in [12]. L41 and L44 have FGR one order of magnitude higher than L44, which can be expected as the average LHGRs of L41 and L45 were 26\% and $27 \%$ above that of L44, respectively. For all three, the FGR remains contained, similarly to the results of the $\mathrm{U}_{3} \mathrm{Si}_{2}$ fuels. Chemical burnup data will be collected in the coming months to corroborate the calculations and confirm the FGR values. Optical microscopy and chemical burnup analyses are in progress at the time of writing.

Table 3. Fission gas release data and calculated burnup and fission density for the three LANL rodlets.

\begin{tabular}{|c|c|c|c|c|c|}
\hline Rod ID & $\begin{array}{c}\text { Calculated burnup } \\
\text { (GWd/tHM) }\end{array}$ & $\begin{array}{l}\text { Calculated fission } \\
\text { density (fiss } / \mathbf{c m}^{3} \text { ) }\end{array}$ & $\begin{array}{c}\text { Plenum pressure } \\
(\mathrm{MPa})\end{array}$ & $\begin{array}{l}\text { Plenum pressure } \\
\text { uncertainty }(\%)\end{array}$ & $\begin{array}{c}\text { Estimated FGR } \\
(\%) \\
\end{array}$ \\
\hline L41 & 9.99 & $3.15 \mathrm{E}+20$ & 0.105 & 7.83 & 0.20 \\
\hline L44 & 9.46 & $3.04 \mathrm{E}+20$ & 0.102 & 11.03 & 0.01 \\
\hline L45 & 13.19 & $2.60 \mathrm{E}+20$ & 0.110 & 6.65 & $0.64^{\mathrm{a}}$ \\
\hline
\end{tabular}

a. The value has been corrected from the previously reported value of 0.70 as a more accurate density value of the fuel stack has been used.

\subsection{ATF-10, ATF-30 and ATF-34: PIE Results and Discussion}

Visual inspection was performed on the rodlets at four different azimuthal angles. The photos taken at $0^{\circ}$ orientation are shown in Figure 10, Figure 11 and Figure 12 for W01, WB2 and WB6, respectively, with the rodlet bottom positioned towards the left of the image. A metric ruler is shown above the rodlets. No unusual features or large defects were detected on the cladding surface. Darkening of the cladding has occurred around the welding of the end caps, similarly to the other rodlets.

Radiographs of the rodlets were taken at 3 different angles $60^{\circ}$ apart. The neutron radiography at $240^{\circ}$ is shown in Figure 11. The drilled pellets at the top of W01 are visible on the left pin. At the top of WB2 and WB6, the melt packs are visible. The lower half of W01 looks cracked, similarly to the pins previously analyzed. The upper left part of the third enriched pellet is missing. It is known that some cracks occurred during fabrication of this first generation-type pellets, but it is obvious from the PIE that irradiation has caused pellet cracking. Regarding the other two rodlets, cracks perpendicular to the rodlet axis are visible along the fuel stack. Those cracks are found either at pellet mid plane or near the pelletpellet interface, suggesting that the latter could have been induced by loading during thermal expansion. The angle-averaged measured diameters for the rodlets is shown in Figure 12 for W01, Figure 13 for WB2 and Figure 14 for WB6. Some swelling occurred in W01, but overall the pin outer diameter remains close to the fabrication value. The outer diameter value of W01 remains close to the one measured for W06, reported for comparison. The behavior for both WB2 and WB6 is different. It is obvious from the two figures that cladding strain has occurred locally at the pellet-pellet interface. The behavior is more pronounced in WB6, particularly in the middle of the active stack. The trend is consistent with the higher thermal expansion consequence of the higher irradiation temperature in this rodlet.

The axial distribution of the major gamma emitters in rodlet W01, shown in Figure 15a, is comparable with what observed previously for the other two $\mathrm{U}_{3} \mathrm{Si}_{2}$ rodlets. No fission product axial distribution is visible in the scans of WB2 and WB6 as well (Figure 15b and c, respectively). The absence of counts between the enriched stack and the upper depleted pellet corresponds to the location of the melt packs visible in Figure 11. Gamma tomography data have been gathered for WB2. The two-dimensional distributions of $\mathrm{Zr}-95$, Cs-137, and $\mathrm{Ru} / \mathrm{Rh}-106$ are reported in Figure 16. The areal distribution of all the products remains fairly homogeneous. A minor increase in the fission product concentration along the pellet periphery was expected due to the local increase of burnup following self-shielding, which is typical of a thermal neutron spectrum. 


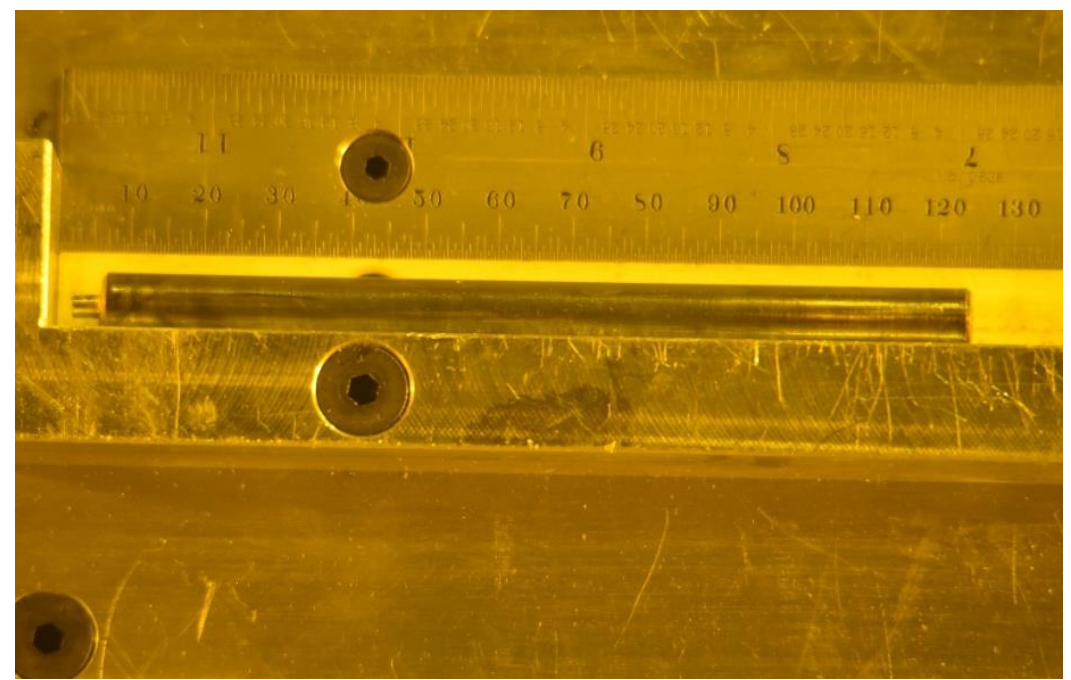

(a)

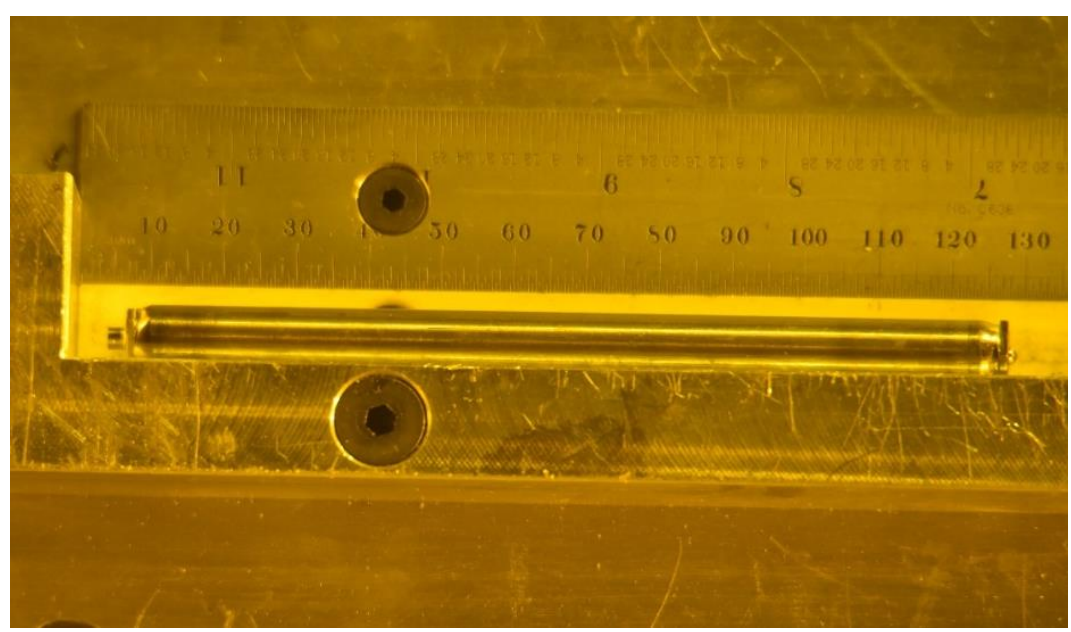

(b)

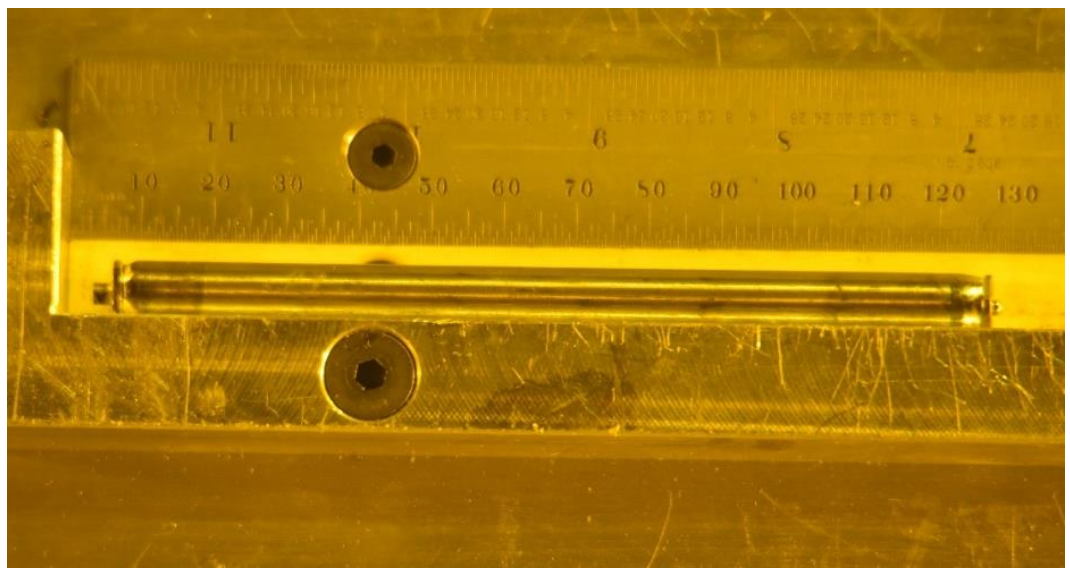

(c)

Figure 10. (a)-(c) Visual examinations of rodlet (a) W01 (b) WB2 and (c) WB6. 


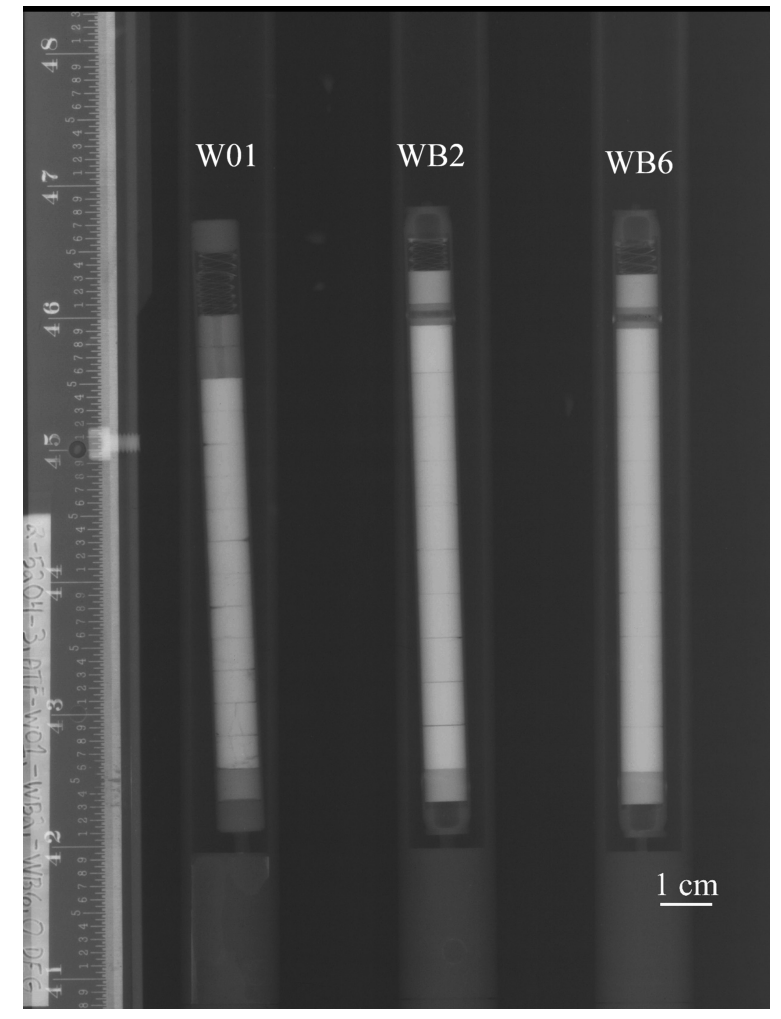

(a)

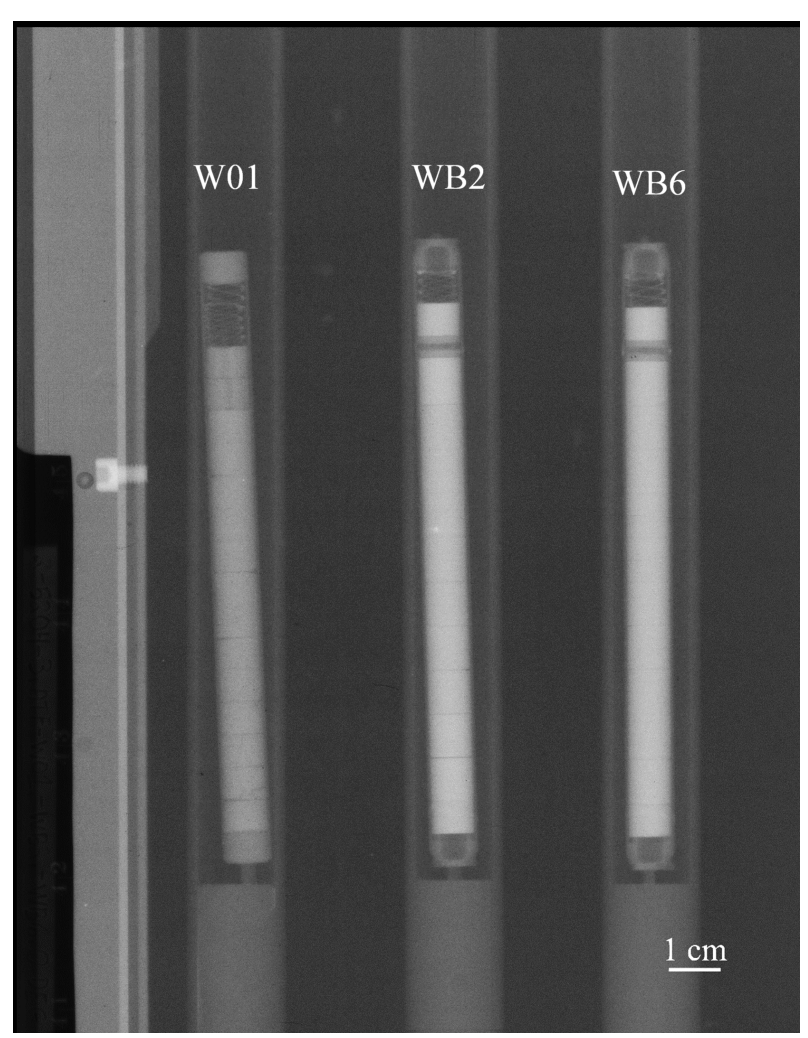

(b)

Figure 11. (a) Thermal neutron radiography of the three rodlets, (b) epithermal neutron radiography at the same azimuthal angle.

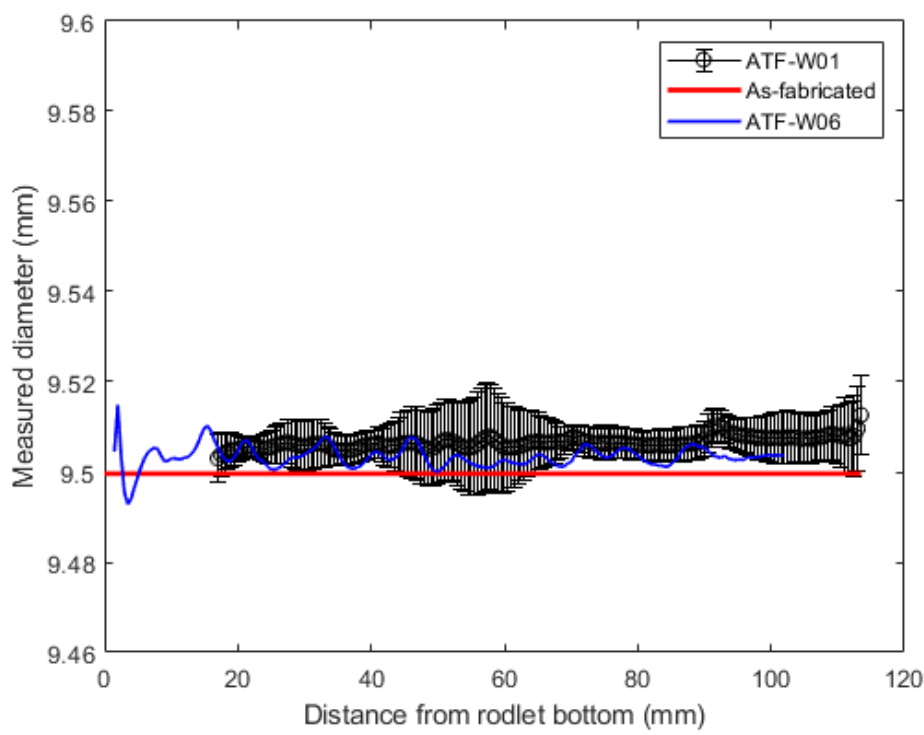

Figure 12. Measured cladding outer diameter for rodlet W01 (black symbols). For reference, the as-fabricated value is shown (red line) as well as the average profilometry results from one of the previous analyzed U3Si2Zirlo rodlets [13]. 


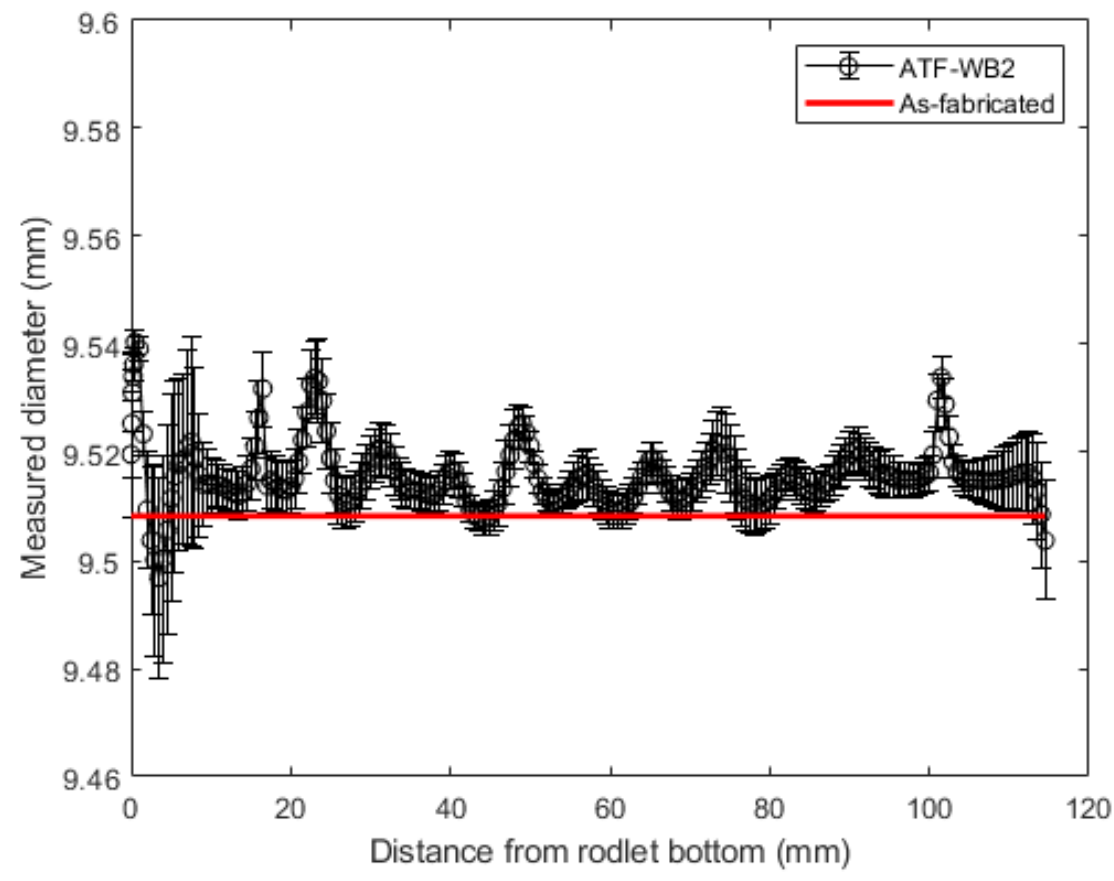

Figure 13. Cladding outer diameter data for WB2 (black symbols) and as-fabricated rodlet outer diameter (solid red line). 


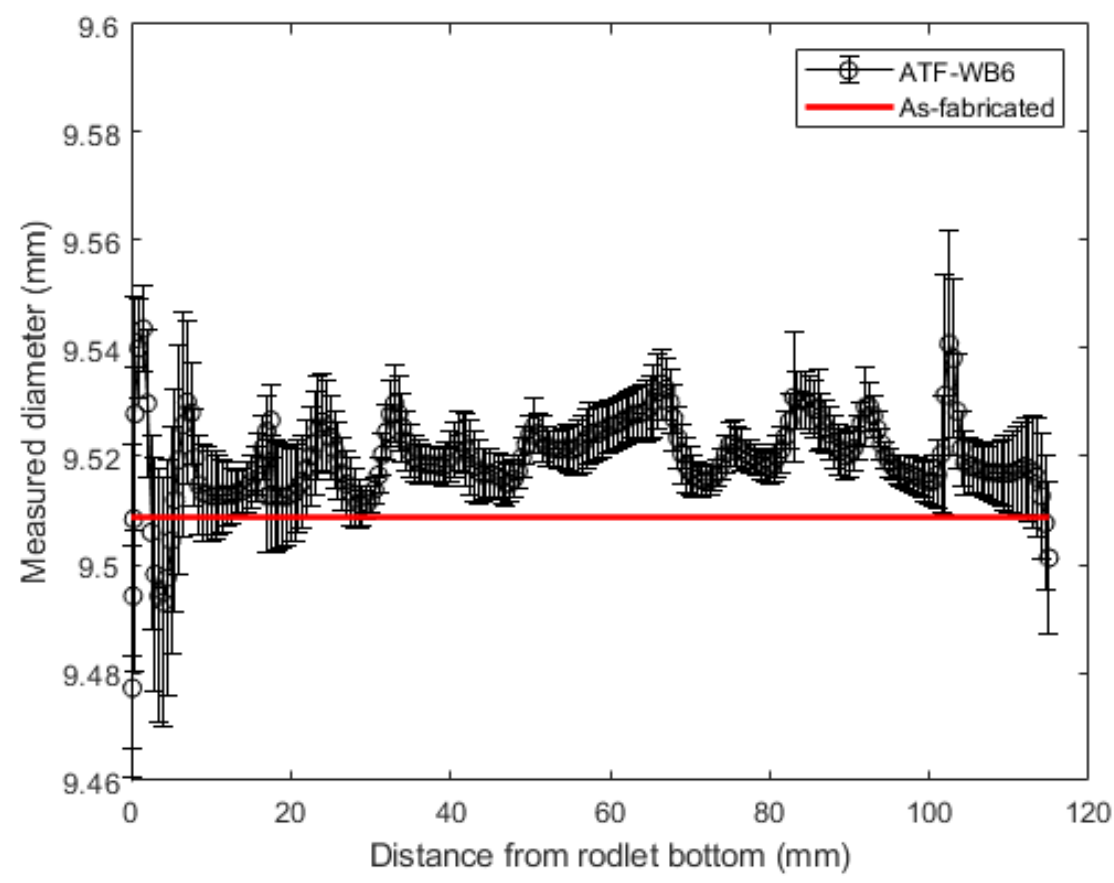

Figure 14. Cladding outer diameter data for WB6 (black symbols) and as-fabricated rodlet outer diameter (solid red line).

(a)

(b)

(c)

Figure 15. Axial gamma profile of Cs-137 and Ce/Pr-144 for rodlets (a) W01, (b) WB2, and (c) WB6. 


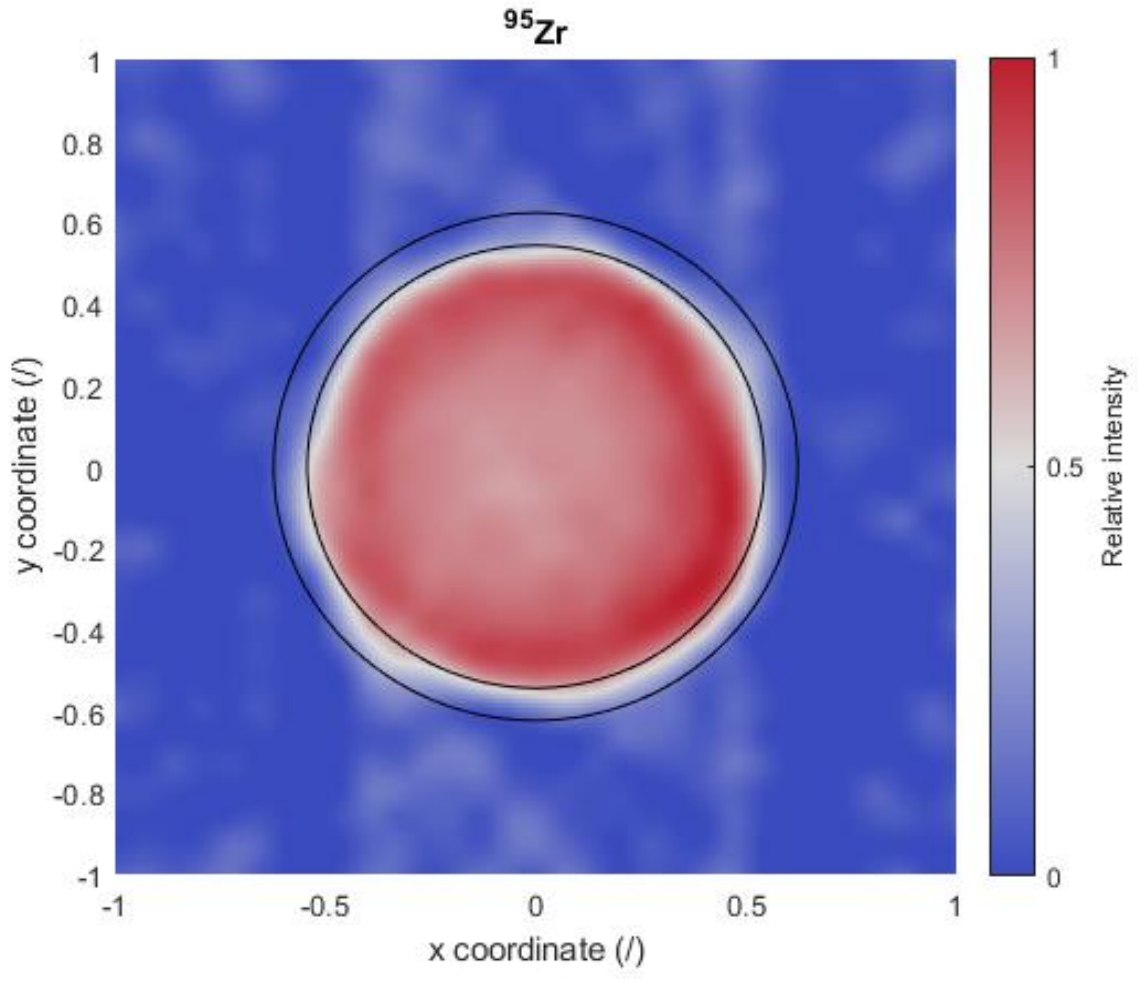

(a)

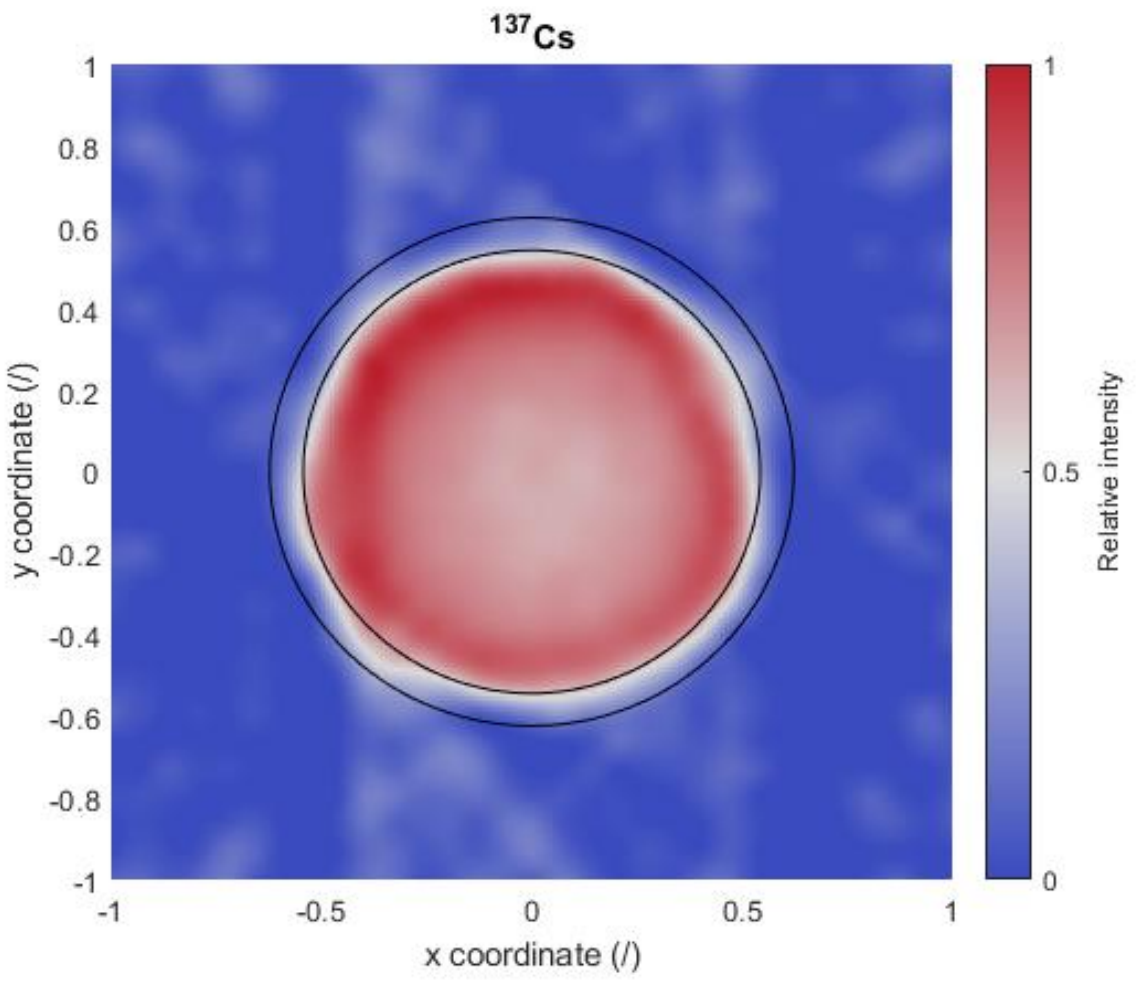

(b) 


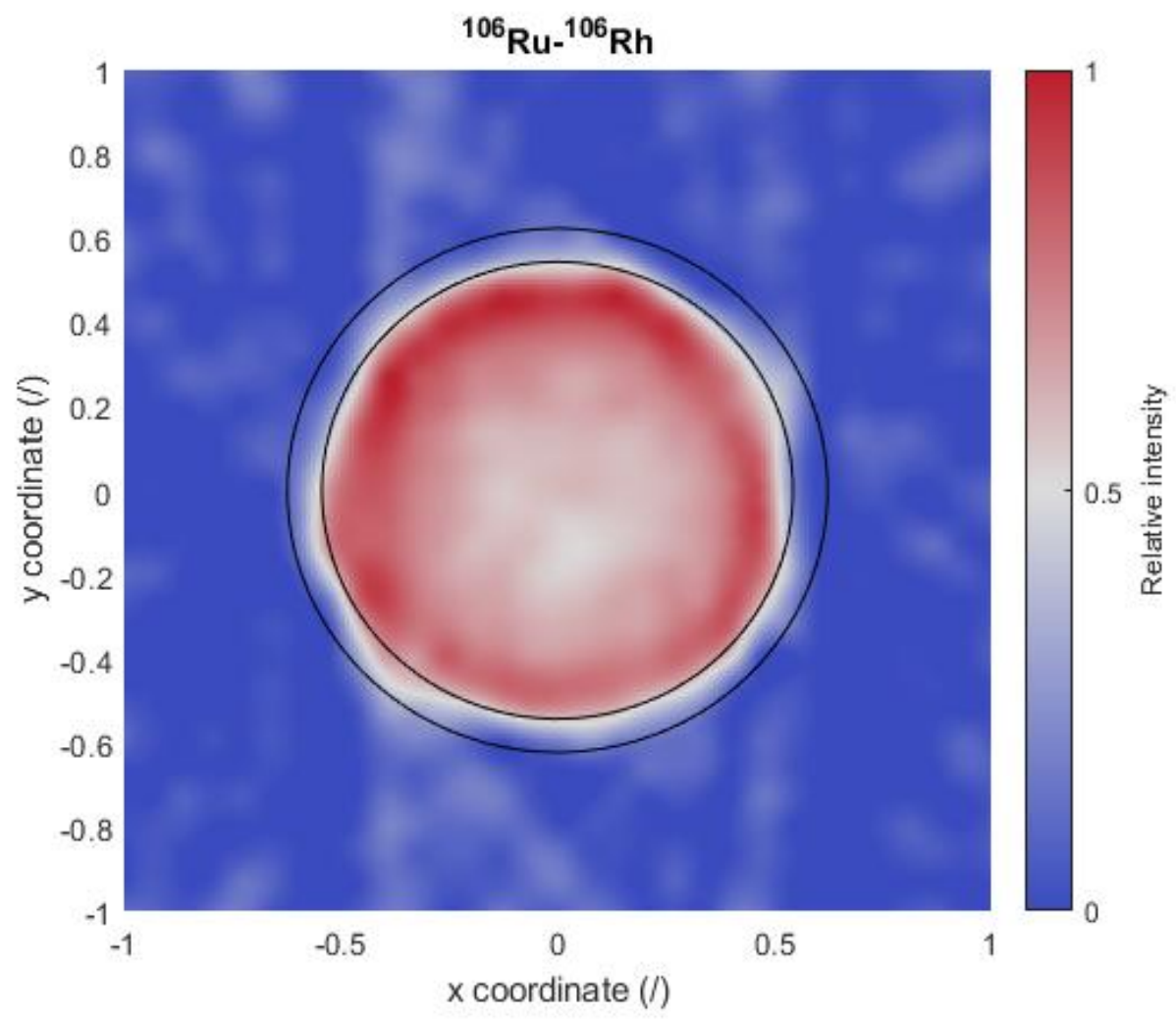

(c)

Figure 16. Radial distribution of selected fission products from gamma tomography on rodlet WB2. (a) 95Zr, (b) $137 \mathrm{Cs}$, (c) 106Ru-106Rh. All the data were collected at the axial mid plane of the rodlet. 


\subsection{Other ATF-1 PIE}

As mentioned in the introduction, the remaining ATF-1 capsules have been discharged during the second quarter of the year and were received in the hot cells in May 2020. Visual examinations of all the fourteen capsules have been completed. All capsules were intact and in good conditions. An example is reported in Figure 17, which shows one of the two Oak Ridge National Laboratory (ORNL)-sponsored capsules containing the rodlets for the $\mathrm{UO}_{2}-\mathrm{FeCrAl}$ fuel-cladding chemical interaction (FCCI) experiment matrix.

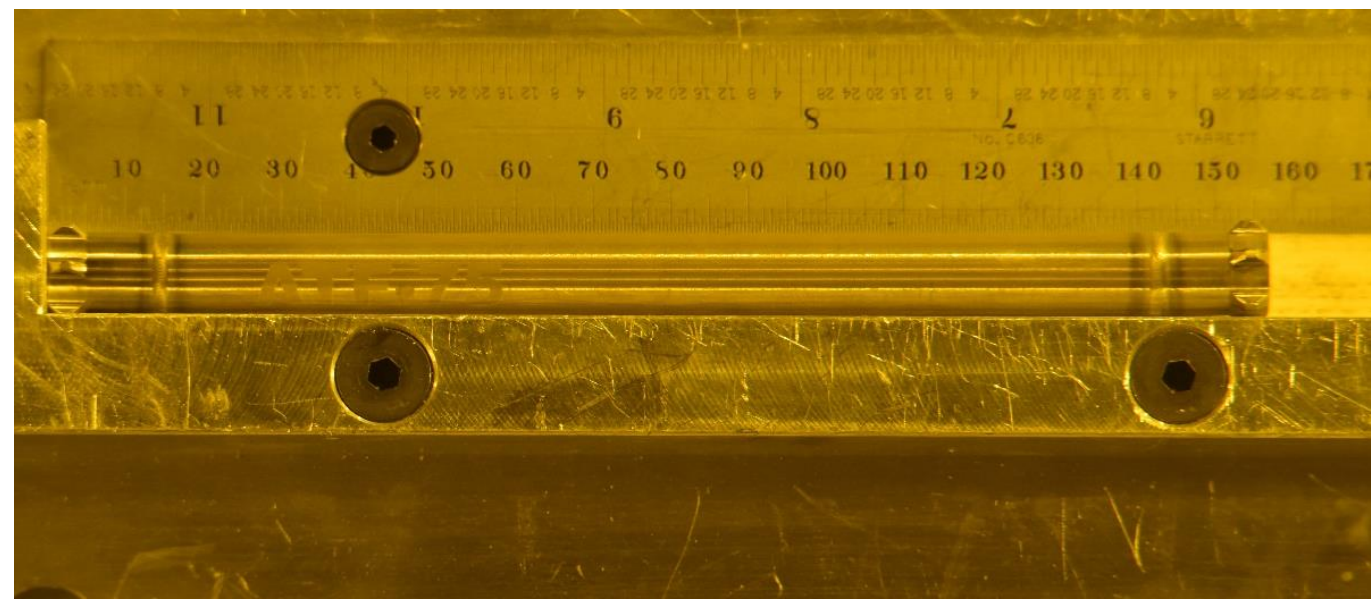

Figure 17. Visual examination of capsule ATF-75 (rodlet ATF-OF3).

\subsection{ATF-2 PIE}

This PIE campaign was focused on the baseline rodlets to provide a direct comparison for the performance of the coated cladding as well as to have a pre-transient database to evaluate the microstructural and properties changes after the dry-out transients planned in TREAT for some of these rodlets [14]. A total of seven rodlets were received at the INL HFEF in February 2020. The rodlets underwent visual examination and gamma spectroscopy. In a second stage, four out of the seven rodlets were selected for further examinations. Profilometry and neutron radiography were executed to complete the initial dataset. All the experimental details have been already reported earlier this year [15]. Overall, from the non-destructive examinations, no unusual features were observed in any of the rodlets. None of the examinations revealed behavior outside of what is considered standard performance for low burnup $\mathrm{UO}_{2}-\mathrm{Zr}-4$ fuel. At the time of writing, two of the seven rodlets are undergoing fission gas release measurements, which will be followed by destructive examinations. 


\section{CONCLUSIONS}

PIE on several ATF-1 and ATF-2 rodlets has been executed. The ATF-1 PIE focused on the continuation of the analyses of five rodlets, one containing $\mathrm{U}_{3} \mathrm{Si}_{2}$ fuel, two containing $\mathrm{UN}-\mathrm{U}_{3} \mathrm{Si}_{5}$ composites, and two with $\mathrm{UN}-\mathrm{U}_{3} \mathrm{Si}_{2}$ composites.

The non-destructive examinations of the $\mathrm{U}_{3} \mathrm{Si}_{2}$ rodlet showed results comparable with the previously investigated rodlets. Already at relatively low burnup, i.e., approximately $20 \mathrm{GWd} / \mathrm{tHM}$, the $\mathrm{UN}-\mathrm{U}_{3} \mathrm{Si}_{2}$ rodlets showed that pellet-cladding mechanical interaction (PCMI) occurred. The profilometry of the $\mathrm{UN}-\mathrm{U}_{3} \mathrm{Si}_{2}$ composites highlighted permanent deformation of the cladding at the pellet-pellet interface, suggesting that hourglassing of the composite pellet during irradiation caused increased localized stresses on the cladding. The $\mathrm{UN}-\mathrm{U}_{3} \mathrm{Si}_{5}$ rodlets did not show signs of PCMI, but it is known that the initial gap between the fuel and the Kanthal cladding was purposefully fabricated larger than for standard LWR geometries, hence, the larger gap might have accommodated fuel swelling without causing PCMI. Regarding the fission products, no axial redistribution of the major gamma emitters was observed in any of the composite rodlets. Fission gas measurements on the $\mathrm{UN}-\mathrm{U}_{3} \mathrm{Si}_{5}$ rodlets also has been performed.

The estimated fission gas release, based on the calculated fission product inventory, remains limited, with a higher fission gas release for the rodlet that experienced a higher power. Further destructive examination data are being collected to complete the assessment of the performance of these new fuels.

In addition to the PIE data on the ATF-1 concepts, PIE on the baseline rodlets part of the ATF-2 tests irradiated in the water loop installed in ATR commenced this year. All the data collected showed a performance consistent with expectations for this fuel system at low burnup. 


\section{REFERENCES}

[1] J. Carmack, F. Goldner, S.M. Bragg-Sitton, L.L. Snead, Overview of the U.S. DOE Accident Tolerant Fuel Development Program, in: TopFuel 2013, 2013.

[2] S.M. Bragg-Sitton, W.J. Carmack, Phased Development of Accident Tolerant Fuel, in: TopFuel2016, ANS, Boise, ID, 2016: pp. 1207-1215.

[3] D.R. Olander, Behavior of solid fission products in oxide fuel elements, in: Fundam. Asp.

Nucl. React. Fuel Elem., Technical Information Center, Office of Public Affairs Energy Research and Development Administration, 1976: pp. 172-198.

[4] D.R. Olander, Swelling Due to Fission Gases, in: Fundam. Asp. Nucl. React. Fuel Elem., US Department of Energy, 1976: p. 199.

[5] S.C. Middleburgh, R.W. Grimes, K.H. Desai, P.R. Blair, L. Hallstadius, K. Backman, P. Van Uffelen, Swelling due to fission products and additives dissolved within the uranium dioxide lattice, J. Nucl. Mater. 427 (2012) 359-363. doi:https://doi.org/10.1016/j.jnucmat.2012.03.037.

[6] J. Spino, J. Rest, W. Goll, C.T. Walker, Matrix swelling rate and cavity volume balance of UO2 fuels at high burn-up, J. Nucl. Mater. 346 (2005) 131-144.

doi:https://doi.org/10.1016/j.jnucmat.2005.06.015.

[7] C.J. Murdock, J.V. Brookman, C. Xing, Accident Tolerant Fuels Series 1 (ATF-1) Irradiation Testing FY 2019 Status Report, 2019.

[8] B.J. Curnutt, ECAR-4464 ATF-2 As-Run Analysis for ATR Cycles 164A through 164B and Projection Analysis for Cycle 166A, 2019.

[9] B. Curnutt, ECAR-4747 ATF-2 Cycle 166A As-Run and Payload Source Term for 10 Rodlet Shipment, Idaho National Laboratory, 2020.

[10] F. Cappia, J.M. Harp, Post-Irradiation Examination of the ATF-1 Experiments - 2019 Status, 2019.

[11] J.M. Harp, F. Cappia, L. Capriotti, Postirradiation Examination of the ATF-1

Experiments - 2018 Status, United States, 2018. doi:10.2172/1484529.

[12] V. Brookman, B.J. Curnutt, ATF-1 Power histories, 2018. TEV-3119.

[13] F. Cappia, J.M. Harp, Postirradiation examinations of low burnup U3Si2 fuel for light water reactor applications, J. Nucl. Mater. 518 (2019) 62-79.

doi:https://doi.org/10.1016/j.jnucmat.2019.02.047.

[14] D. Kamerman, ATF-R Experiment Execution Plan, PLN-5962, Idaho National Laboratory, 2020.

[15] F. Cappia, Non-destructive Examinations of ATF-2 Baseline Rodlets, Idaho National Laboratory, United States, 2020. doi:10.2172/1637596. 